Keywords: Depression; Anxiety disorder; Depression and anxiety comorbidity; Neuropsychological assessment; Cognitive.

\title{
Comorbidity of anxiety disorders in major depressive disorder. A clinical trial to evaluate neuropsychological deficit
}

\author{
Ixchel Herrera-Guzmán ${ }^{\star, \star \star, \star \star \star}$ \\ Esteve Gudayol-Ferrée ${ }^{\star, \star \star, \star \star \star \star}$ \\ Adolfof Jarne-Esparcia ${ }^{\star * * \star * *}$ \\ Jorge E. Herrera-Abarca*,*** \\ Daniel Herrera-Guzmán ${ }^{\star * \star \star}$

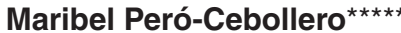 \\ Joan Guàrdia-Olmos ${ }^{\star \star \star \star *}$
}

* Clínica de Enfermedades Crónicas y

Procedimientos Especiales CECYPE, Morelia, Mich., Mexico

** Escuela de Psicología Universidad Michoacana de San Nicolás de Hidalgo, Morelia, Mich., Mexico

*** Escuela Superior de Medicina, División de Estudios de postgrado e Investigación Instituto Politécnico Nacional, I.P.N. Mexico City, Mexico

**** Centro Michoacano de Salud Mental. Secretaría de Salud. Morelia, Mich., Mexico

***** Departament de Metodologia, Facutat de Psicologia, Universitat de Barcelona, Barcelona, Spain

****** Departament de Personalitat, Avaluació i Tractaments Psicològics, Universitat de Barcelona, Barcelona, Spain

MEXICO

SPAIN 
with Pure Major Depressive Disorder (PMDD). Both groups were assessed clinically and neuropsychologically before and after 24 weeks of pharmacological treatment. Neuropsychological performance prior to treatment was comparable in the two groups.

Results: After treatment, both groups showed cognitive improvement in attention tasks, memory, and executive functions

Conclusions: The PMDD group obtained greater neurocognitive benefits from the antidepressive treatment than the MDDAD group.

Received 13 April 2008

Revised 4 October 2008

Accepted 17 October 2008

\section{Introduction}

Patients suffering from major depressive disorder (MDD) usually present deficits in a range of cognitive functions ${ }^{1,2}$. The neuropsychological deficit in depressed patients has been observed in measures of attentional functions ${ }^{3,4}$, speed of information processing and motor functioning ${ }^{5,6,7}$, episodic memory ${ }^{2,8,9}$, work memory ${ }^{10}$, and executive functions ${ }^{1,7}$. Other recent work suggests that MDD may also cause bias in the processing of affective information, abnormal responses to negative feedback, and deficits in decision-making ${ }^{11}$. The impact of cognitive deficits on the everyday functioning of patients with MDD (Life functioning) is a subject that has not been explored in depth, despite the fact that a recent study ${ }^{12}$ suggests that the presence of neuropsychological deficits substantially hinders functional recovery in at least some depressed patients. That study also suggests that the presence of motor and memory deficits predicts poor recovery of patients' everyday functioning.

Episodic memory impairment is a prominent deficit in patients with $\mathrm{MDD}^{2,8,13}$. Some studies suggest that patients with MDD present episodic memory impairment in free and cued recall tasks ${ }^{8}$. A possible explanation for this memory deficit is that MDD is associated with functional and structural changes in the hippocampus ${ }^{14,15}$ and the prefrontal cortex ${ }^{1}$, both of which are critical structures for the correct functioning of episodic memory.

Similarly, it has been observed that depressed patients often present deficits in their speed of information processing, especially in complex tasks ${ }^{6,7}$. Some authors suggest that these deficits in MDD patients are due to a dopaminergic dysfunction in frontostriatal structures ${ }^{5,16}$.

Major Depressive Disorder is an illness that usually manifests with deficits in the executive functions. Patients with MDD often present deficits in verbal fluency tests $^{17,18}$, set shifting ${ }^{10,19,20}$, planning ${ }^{21,22}$, and automated response inhibition ${ }^{10,17,22}$. These functions are controlled by the prefrontal cortex and the circuits that some of its different parts establish with the thalamus and the basal ganglia ${ }^{22,23}$. This provides a possible explanation for the dysfunctions often found in depressed patients ${ }^{1}$.

Attention deficits have also been reported in patients with $\mathrm{MDD}^{3,4}$. Some studies suggest that depressed patients have sustained attention deficit ${ }^{24}$; others show that attention deficits are prominent in remitted patients with MDD, and it has been proposed that a sustained attention deficit may represent a trait vulnerability marker in $\mathrm{MDD}^{4}$. One 
study suggests that abnormalities in frontothalamic-striatal networks cause attention deficit in $\mathrm{MDD}^{22}$.

Several clinical aspects of depression are related to the neuropsychological deficits that are characteristic of this illness. Cognitive performance in patients with MDD can be affected, to a greater or lesser extent, by clinical variables such as the severity of the illness, patients' age, depression subtype, hospitalization during the depressive episode, and the remission or recovery from a depressive episode ${ }^{19,25}$. Nevertheless, given how complex and numerous these variables are, studies of the neurocognitive aspects of MDD have not dealt with them thoroughly. The presence of comorbid anxiety disorders is a clinical aspect of MDD whose relation to neuropsychological performance is not usually examined. Approximately two thirds of patients with MDD have a comorbid anxiety disorder ${ }^{26}$, and some authors suggest that anxiety and depression symptoms so frequently overlap that the patients with only one disorder are the exception rather than the rule. Patients with MDD and a comorbid anxiety disorder are often more severely ill than patients who only suffer from depression ${ }^{26,27}$, they experience more deficits in social functioning than the patients with only one type of illness ${ }^{26}$, and are more likely to seek clinical help ${ }^{27}$. Both MDD and anxiety disorders show monoaminergic alterations, which provides a possible explanation as to why they are so frequently associated ${ }^{26}$.

Anxiety disorders also manifest themselves with cognitive deficit, although this topic has not been studied in depth. Obsessive-compulsive disorder is probably the anxiety disorder that has been most studied from a neuropsychological point of view, whereas other impairments that are frequently comorbid with MDD - such as panic disorder (PD), social phobia, and generalized anxiety disorder (GAD) - have received less attention. A recent study ${ }^{28}$ found that patients with anxiety disorders suffer greater impairments of their episodic memory and their executive functions (set shifting) than a control group; however, verbal fluency and speed of information processing did not seem to be affected by anxiety disorders ${ }^{8}$. Very few studies have explored the possible effect of anxiety disorders on the neurocognitive performance of patients with MDD. Another study ${ }^{29}$ suggests an association between pure MDD and significant memory problems, and an association between MDD with comorbid anxiety and deficits in verbal fluency and psychomotor slowing.

Cognitive performance in patients with MDD can also be affected by antidepressant treatments, which may improve the cognitive symptoms of the disorder. One study reported an improvement in memory and attention skills in a large sample of depressed patients treated with selective serotonin reuptake inhibitors (SSRI) such as fluoxetine or paroxetine ${ }^{30}$, another one ${ }^{31}$ found beneficial effects of the SSRI sertraline, diminishing psychomotor slowing and improving executive functions of patients with MDD. Gallassi et al. ${ }^{32}$ suggested that the SSRI fluoxetine and the selective noradrenaline reuptake inhibitor reboxetine improved memory in depressed patients. Another study described improvements in attentional functions of depressed patients treated with the tricyclic antidepressant imipramine or the SSRI fluvoxamine $^{24}$. Herrera-Guzmán et al. ${ }^{33}$ found that the noradrenergic-dopaminergic reuptake inhibitor bupropion improved memory and mental processing speed performances in MDD. Levkovitz et al. ${ }^{34}$ demonstrated that fluoxetine, but not the tricyclic antide- 
pressant desipramine, improved memory performance in MDD. Fergusson et al. ${ }^{35}$ have shown that reboxetine but not paroxetine improved sustained attention and speed of cognitive functioning. Taken together, these studies suggest that several antidepressants which act by inhibiting reuptake of one or more monoamines exert positive effects on memory and mental processing speed in patients with MDD.

Despite all these data, very few studies have examined the possible effect of anxiety disorders on the neurocognitive performance of patients with MDD. The aim of the present study was to establish the relation between different clinical variables of MDD - especially the presence of comorbid anxiety disorders - and the neuropsychological performance of a sample of depressed patients selected for a clinical trial of the cognitive effects of a Selective Serotonin Reuptake Inhibitor and a dual Serotonin Noradrenaline Reuptake Inhibitor (SNRI). We also aimed to establish the possible differences in neuropsychological performance between these two types of patient, i.e. those with pure MDD and those who also suffer from a comorbid anxiety disorder, and to explore the effects of antidepressant treatment on cognitive function in MDD patients with and without comorbid anxiety disorders

\section{Method}

\section{Participants}

The protocol was approved by the ethical committee of the Centro Michoacano de Salud Mental. All subjects gave written informed consent before entering the study. Between August 2005 and September 2006, subjects were recruited to carry out a clinical trial on the cognitive effects of SNRI and SSRI treatments. Seventy-three patients aged between 20 and 50 years who met the DSM-IV criteria for major depressive disorder, confirmed with the Mini-International Neuropsychiatric Interview ${ }^{36}$, were included in the study. No patients were taking antidepressants or other psychopharmacological drugs. Subjects were excluded if they did not meet DSM-IV criteria or if they had a past history of any of the following disorders: posttraumatic, obsessive-compulsive, schizophrenic, psychotic, delusional, bipolar or any substance use disorder. Subjects with any present or past disease of the central nervous system, diabetes, hypertension, cardiac, hepatic, pulmonary or renal disease and systemic infectious diseases were also excluded. Laboratory tests were carried out when presence of any illness listed among the exclusion criteria was suspected.

\section{Instruments}

The subjects were assessed by means of HAM-D-17 and a neuropsychological evaluation battery containing paper-and-pencil tests and the Cambridge Neuropsychological Test Automated Battery (CANTAB ${ }^{37,38}$ ). The following is a list of the tests used -organized by cognitive domains- and the variables registered with each test:

- Premorbid intellectual functioning:

- WAIS III vocabulary subtest: Overall score.

- Working memory:

- Wais III Digit span: The longest backward digit span recalled by the subjects 
- Spatial Working Memory (SWM): The total number of errors made by the subjects during the test and the strategy score.

- Verbal learning and memory:

- Rey Auditory Verbal Learning Test (RAVLT): Number of words remembered after a 20-minute interval.

- Visual learning and memory:

- Pattern Recognition Memory (PRM): Total number of correct answers.

- Paired Associates Learning (PAL): Adjusted total number of errors and adjusted total number of trials needed by the subjects to complete the test.

- Delayed Matching to sample (DMS): Overall number of correct answers.

- Speed of information processing:

- Stroop Test: Two variables: Number of words read by the subjects in 45 seconds (STROOPW), and number of colors named by the subjects in 45 seconds (STROOPC).

- Attention:

- Rapid Visual Information Processing (RVP): Overall number of correct answers.

- Executive functions. inhibition:

- Stroop Test: Number of colors named by the subjects in 45 seconds in the interference condition (STROOPI).

- Executive functions. fluency:

- Controlled Oral Word Association Test (COWAT): Overall number of correct answers.

- Five Point Test (FP): Total number of correct designs produced by the subjects in 3 minutes.
- Executive funcions. set shifting:

- Intra/Extra Dimensional Set Shifting (ID/ED): Adjusted total number of errors made by the subject while completing the test, and the adjusted total number of trials needed to complete the test.

- Executive functions. planning:

- Stockings of Cambridge (SOC): Mean initial time needed by the subject to plan 5-move problems and the overall problems solved with minimum moves.

\section{Procedure}

We applied Hamilton's scale for depression severity (HAM-D-17) to all the patients and used a clinical interview to record patients' age and gender, years of formal education, information on the presence and number of past MDD episodes, and the age of their first depressive episode. Using MINI, we studied the presence of symptoms of melancholy, suicidal risk, and the following anxiety disorders: Panic attack, agoraphobia, social phobia and generalized anxiety disorder. We also measured the number of comorbid anxiety disorders.

All the patients were assessed with the neuropsychological battery and were treated with selective SSRI escitalopram $(n=35)$ or the SNRI duloxetine $(n=37)$ for 24 weeks. At the end of the treatment they were assessed again with HAM-D-17, MINI and the same neuropsychological protocol (except the WAIS III vocabulary subtest), using parallel forms of the tests when available. 


\section{Results}

All the analyses presented below were run with the SPSS program, version 15.0. Firstly, we obtained descriptive statistics for the whole sample from the dichotomous clinical variables, resulting in the distribution observed (presence/absence) for the following variables: Melancholy, suicidal risk, panic attack, agoraphobia, social phobia, generalized anxiety disorder and comorbidity. We also obtained descriptive statistics for the following variables: Age, years of formal education, WAIS III vocabulary, Hamilton's scale before treatment, age at first episode, number of episodes up to that moment, and number of comorbid disorders diagnosed. With the values observed in all those variables, we explored the viability of obtaining coherent clusters with the previously described clinical features of depression. In order to do so, we opted for a cluster between subjects hierarchized in two stages, thus obtaining two groups (clusters) clearly differentiated from one another by the following variables: number of episodes, number of comorbid disorders, and level of anxiety. On the basis of these three variables we were able to define two groups: the first one comprising 51 subjects $(69.9 \%$ of the sample), with Major Depressive Disorder and a Comorbid Anxiety Disorder (MDDAD), and the second comprising 22 subjects $(30.1 \%$ of the sample) suffering only from Pure Major Depressive Disorder (PMDD).

Next, socio-demographic and quantitative clinical variables and variables relating to pre-treatment neuropsychological performance were compared in the two groups using the Student-Fisher's $t$ test (see Table I). In order to reduce the nominal level of alpha risk we interpreted all the results with a threshold of $\mathrm{p}<0.01$, obtaining the follow- ing statistically significant differences: age $(\mathrm{t}$ $=2.912 ; \mathrm{df}=71 ; \mathrm{p}=0.005)$ and number of past depressive episodes $(\mathrm{t}=3.687$; $\mathrm{df}=71 ; \mathrm{p}$ $<0.001)$, and a trend towards significance in age at first depressive episode $(\mathrm{t}=2.241 ; \mathrm{df}=$ $71 ; p=0.028)$. Table I shows the comparison between the initial Hamilton's scale scores for each group, which found a statistically significant difference $(\mathrm{t}=2.854 ; \mathrm{df}=71 ; \mathrm{p}=$ $0.006)$ between the two means. No statistically significant differences were found between the groups before treatment in the neuropsychological performance variables.

In addition, in order to assess the change undergone by subjects after the pharmacological treatment, the ratio of the change was calculated for each subject in each neuropsychological variable. Therefore, the following transformation was applied to every variable:

Ratio $=[($ Second mean value - First mean value)/First mean value]

This operation provided us with an estimation of the change in relation to the first measure which matched the scale range $(0-1)$ of all the variables and allowed us to assess them all together. Having observed the means of all the variables, we compared each variable in each group with respect to the 0 value (which would indicate null change) using the Student-Fisher's $t$ test. We obtained statistically significant differences in the following variables for the MDDAD group: RAVLT delayed recall $(\mathrm{t}=$ 5.922; df $=50 ; \mathrm{p}<0.001)$, STROOPI $(\mathrm{t}=$ $4.419 ; \mathrm{df}=50 ; \mathrm{p}<0.001), \mathrm{RVP}$ total hits $(\mathrm{t}$ $=3.347 ; \mathrm{df}=50 ; \mathrm{p}=0.002)$, COWAT correct answers $(\mathrm{t}=5.491 ; \mathrm{df}=50 ; \mathrm{p}<0.001)$, FP correct designs $(\mathrm{t}=6.293$; $\mathrm{df}=50 ; \mathrm{p}<$ 0.001 ), and SOC problems solved in minimum moves $(\mathrm{t}=3.188$; $\mathrm{df}=50 ; \mathrm{p}=0.002)$; and a tendency in STROOPW $(\mathrm{t}=2.358$; $\mathrm{df}$ $=50 ; \mathrm{p}=0.022)$ and STROOPC $(\mathrm{t}=2.300$; 


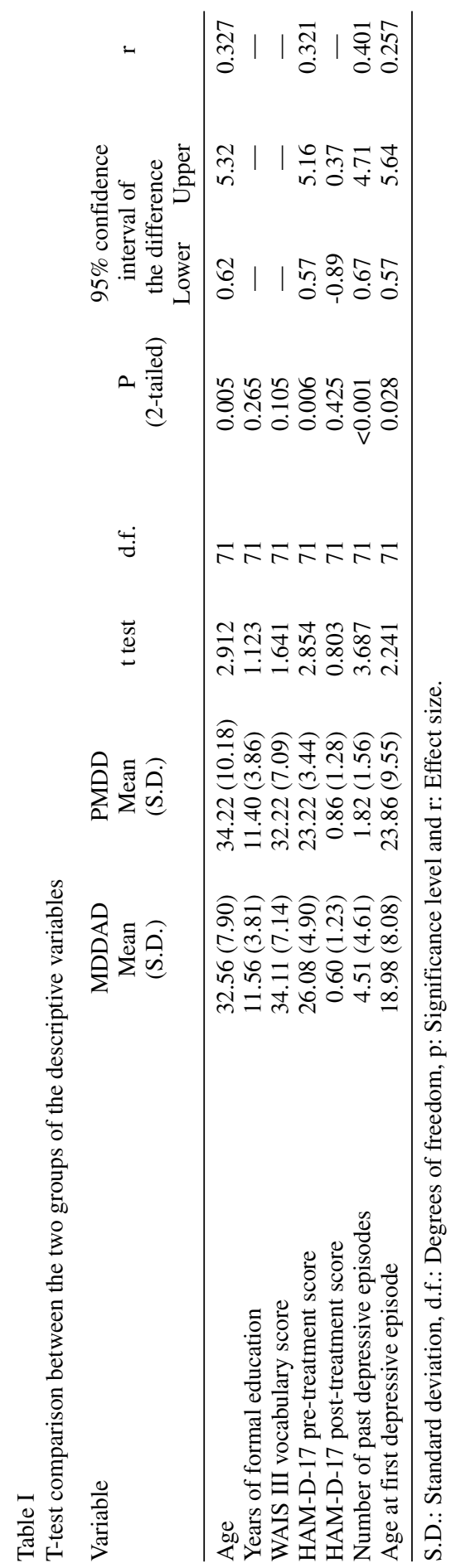

$\mathrm{df}=50 ; \mathrm{p}=0.026)$. Likewise, we obtained statistically significant differences in the following variables for the PMDD group: RVP total hits $(\mathrm{t}=3.529 ; \mathrm{df}=21 ; \mathrm{p}=0.002)$, COWAT correct answers, $(\mathrm{t}=3.248$; $\mathrm{df}=21$; $\mathrm{p}=0.004)$, FP correct designs $(\mathrm{t}=3.539 ; \mathrm{df}$ $=21 ; \mathrm{p}=0.002)$ and SOC mean initial thinking time 5 movements $(\mathrm{t}=3.205 ; \mathrm{df}=21 ; \mathrm{p}=$ $0.004)$; and a trend towards significance in Digits Backward $(\mathrm{t}=2.250 ; \mathrm{df}=21 ; \mathrm{p}=$ 0.035), RAVLT delayed recall $(\mathrm{t}=2.291$; $\mathrm{df}$ $=21 ; \mathrm{p}=0.032)$, PRM correct number $(\mathrm{t}=$ $2.320 ; \mathrm{df}=21 ; \mathrm{p}=0.030)$, STROOPW $(\mathrm{t}=$ $2.549 ; \mathrm{df}=21 ; \mathrm{p}=0.019)$ and SOC problems solved in minimum moves $(\mathrm{t}=2.340 ; \mathrm{df}=$ $21 ; p=0.029)$. These results are displayed in Table II.

Subsequently, the mean observed for each of the distributions according to groups provided us with a comparison $t$ of independent samples with ANCOVA test controlling by age, age at first depressive episode, number of past depressive episodes and initial values of Hamilton's scale. We were thus able to determine whether the clinical groups differed in terms of their observed mean ratio of change. No covariate effect was significant. We obtained statistically significant differences in RWP total hits $\left(\mathrm{F}=5.21 ; \mathrm{p}=0.010 ; \varepsilon^{2}=0.285\right)$; and a trend towards significance in the following variables: STROOPI $(\mathrm{F}=3.18 ; \mathrm{p}=$ $\left.0.021 ; \varepsilon^{2}=0.218\right)$, Five Point Correct Designs $\left(F=3.44 ; p=0.045 ; \varepsilon^{2}=0.226\right)$, Pattern Recognition Memory number of correct responses $\left(\mathrm{F}=4.12 ; \mathrm{p}=0.021 ; \varepsilon^{2}=\right.$ $0.228)$ and SOC mean initial thinking time 5 movements $\left(\mathrm{F}=4.24 ; \mathrm{p}=0.020 ; \varepsilon^{2}=\right.$ 0.291). These results are shown in Table III.

Finally, in order to assess the possible effect of the pharmacological treatment received, we analysed whether there was an interaction effect between type of drug and clinical group, using ANOVA. The follow- 


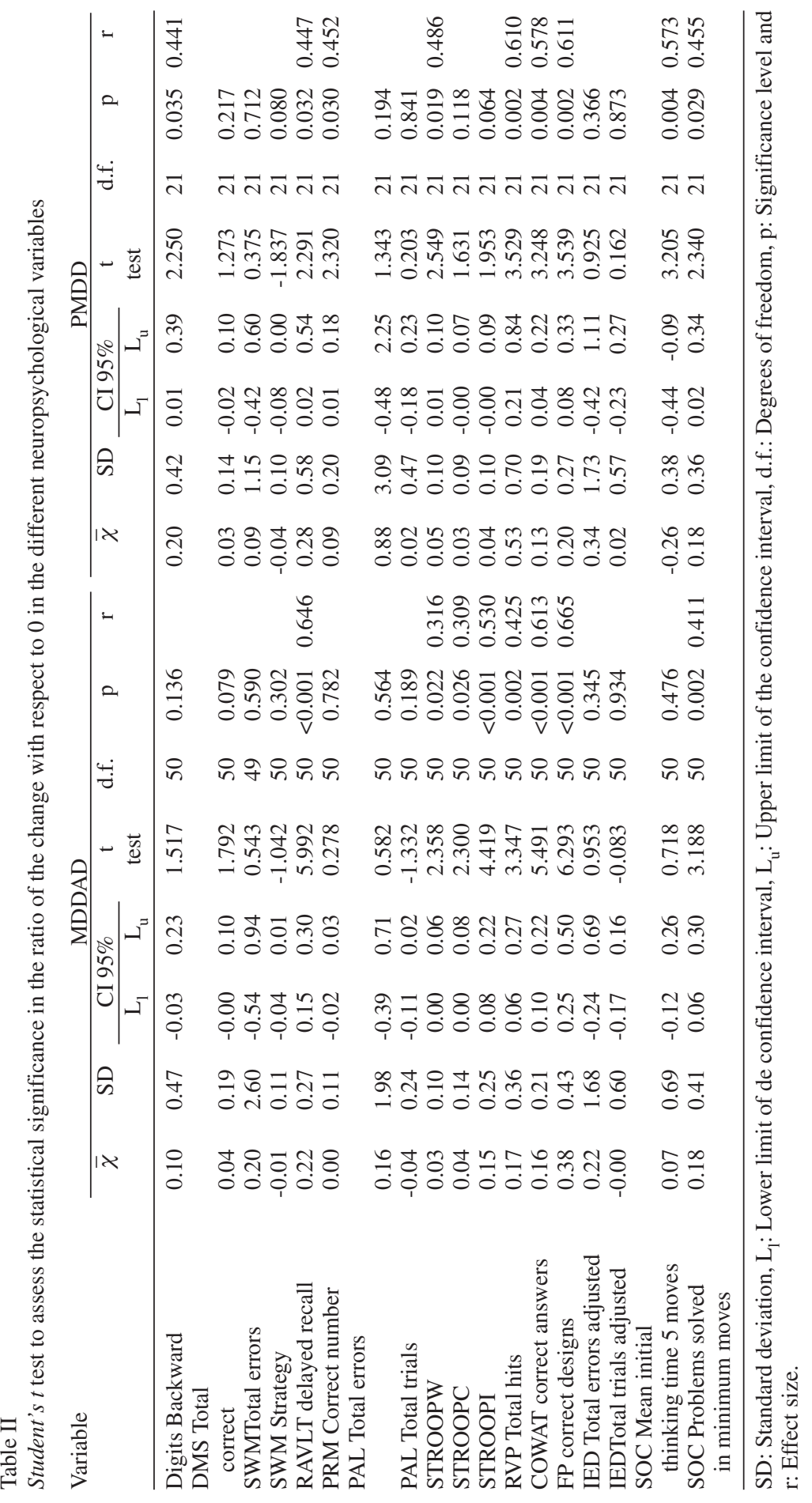




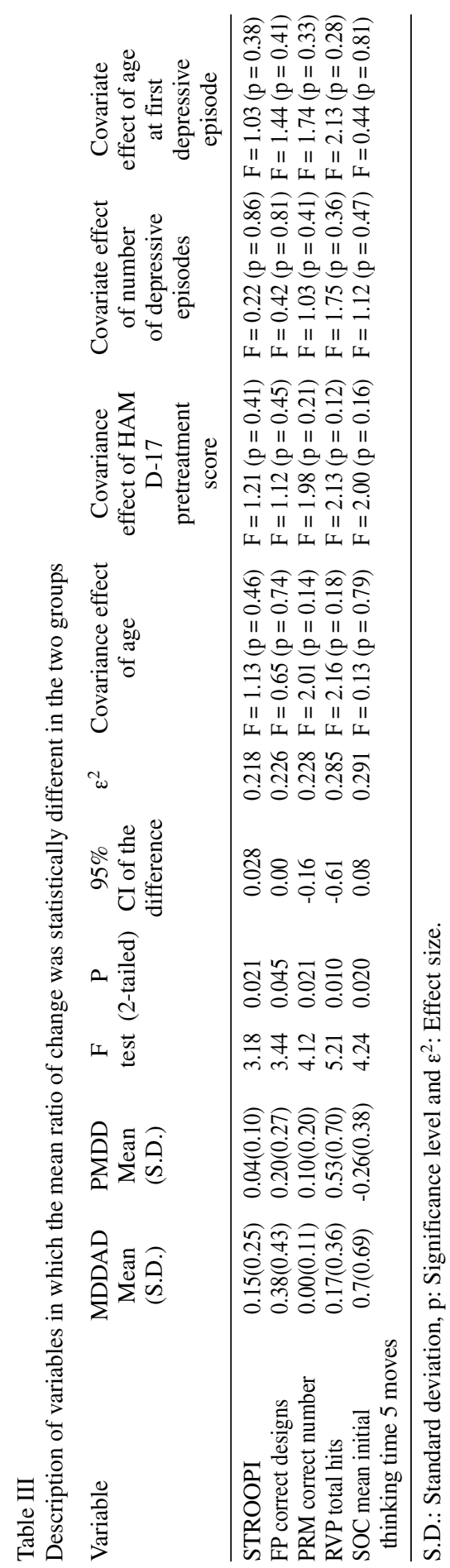

ing effects were significant: PAL total errors adjusted $\left(\mathrm{F}_{(2.69)}=13.490 ; \mathrm{p}<0.001 ; \varepsilon^{2}=\right.$ $0.164)$, and PAL total trials adjusted $\left(\left(\mathrm{F}_{(2.69)}\right.\right.$ $\left.=13.798 ; \mathrm{p}<0.001 ; \varepsilon^{2}=0.167\right)$.

Moreover, the comparison between mean values on the Hamilton scale after 24 weeks of treatment did not show significant effects $(\mathrm{t}=-0.803 ; \mathrm{p}=0.425)$, while all the subjects were asymptomatic and with values consistent with the absence of depression. Therefore, the therapeutic effect manifested itself equally in both clinical groups. In general, the improvement observed in the mean ratio obtained from the sample analyzed between the pre- and post- phases of the treatment is consistent with the improvement in the cognitive functions reported after the disappearance of the depressive symptomatology.

\section{Discussion}

In a clinical trial designed to measure the neurocognitive effects of SSRI and SNRI treatments in a sample of patients with MDD, we found that two distinct groups emerged. The first one $(n=51)$ comprised patients with MDD and a comorbid anxiety disorder (MDDAD), and the second one $(\mathrm{n}=22)$ patients with pure MDD (PMDD). The main feature of the first group is that the subjects suffering from major depression with some anxiety disorder - generalized anxiety disorder in most cases - were younger and had suffered more past MDD episodes than the PMDD group; equally, their current depressive episode, measured with the HAM-D-17, was more severe than that of the PMDD patients. This division into natural groups is consistent with the findings of previous studies on the comorbidities between major depressive disorder and anxiety disorders: the literature reports 
that patients with pure depressive disorder are usually the exception rather than the rule $^{26}$ and moreover, depressed patients who also suffer anxiety disorders are more likely to seek clinical help ${ }^{27}$. All this may explain why our MDDAD group was larger than our PMDD group. Equally, the fact that the MDDAD patients had suffered more past depressive episodes, were younger at the time of the first depressive disorder, and presented more severe depressive symptomatology than the patients from the PMDD group is also consistent with previous reports ${ }^{26,27}$.

Comparison of the baseline cognitive functioning of the MDDAD and PMDD groups did not reveal significant differences in the neuropsychological variables studied. This is a surprising discovery, since the study by Airaksinen et al. ${ }^{8}$ suggested that the different anxiety disorders cause memory and executive function deficits, and showed the memory deficits of its patient sample could not be accounted for by comorbid depression. The study by Basso et al. ${ }^{29}$ showed that patients with MDD and comorbid anxiety disorders suffered exacerbated neuropsychological impairment compared with pure MDD patients and with a control group. Specifically, depressed patients with anxiety disorders, but not pure MDD subjects, showed verbal fluency impairments compared with the control group, and also showed psychomotor slowing relative to both pure MDD patients and controls $^{29}$. Other studies have found that in geriatric patients, serious memory deficit is more frequent in those with MDD and generalized anxiety than in those with MDD alone ${ }^{39}$. For these reasons, it would be natural to expect patients from the MDDAD group to show greater deficits in one or more cognitive areas than the PMDD group. In the MDDAD group, the anxiety disorder suffered by the greatest number of patients was generalized anxiety disorder. There are several possible explanations for the discrepancy between Basso et al.'s ${ }^{29}$ results and ours. First, Basso et al.'s ${ }^{29}$ patients were tested during an impatient admission, and all were medicated. Furthermore, most of the patients in the MDDAD group in our study suffered from generalized anxiety disorder, while Basso et al.'s patients ${ }^{29}$ with MDD and comorbid anxiety suffered a wide variety of anxiety disorders, with the exception of obsessive-compulsive disorder.

The study by Airaksinen et al. ${ }^{8}$ did not find that this pathology caused any cognitive deficit, but the authors stressed that this might be due to the fact that their subgroup of patients with generalized anxiety disorder was very small. Nevertheless, we should note that our sample was formed by relatively young subjects, something that could account, at least partially, for the discrepancies between our results and those of De Luca et $a l .{ }^{39}$.

Our MDDAD patients had suffered more past depressive disorders, were younger at the onset of MDD, and presented more severe depressive symptomatology than the patients in the PMDD group. But this does not seem to affect the baseline neuropsychological performance. Several studies have associated the severity of depressive symptomatology in MDD with worse neurocognitive performance ${ }^{19,21,40}$, whereas others have found no such relation ${ }^{2,25,41,42,43}$. The relation between these two variables has classically been studied by correlating neuropsychological performance to Hamilton's scale scores $^{2,25}$. We compared the performance of the MDDAD and PMDD groups of our study with the Student-Fisher's $t$ test, so the aforementioned papers do not provide an entirely suitable framework in which to discuss our results. Several studies have reported that a higher number of depressive episodes is 
associated with poorer performance on memory tasks in patients with $\mathrm{MDD}^{29,44}$. Our results are in accordance with those of Lampe, Sitskoon and Heeren ${ }^{45}$ in which the number of depressive episodes did not seem to affect the neuropsychological performance of a sample of depressed patients.

Comparing the patients' neuropsychological performance before and after the pharmacological treatment, the analysis showed that both groups improved in verbal memory measures, speed of information processing, automatic response inhibition, fluency, sustained attention and spatial planning. The PMDD group also presented improvements in working memory and visual recognition memory that were not observed in the MDDAD group. Likewise, after the treatment, the PMDD group presented greater improvement than the MDDAD in measures of visual recognition, sustained attention and spatial planning. For their part, after treatment, the MDDAD group presented greater improvement than the PMDD group in measures of fluency and automatic response inhibition. In the study of second-order interactions (clinical group $\mathrm{x}$ pharmacological treatment $x$ moment of measure), it was observed that the patients from the PMDD group who were administered SNRI treatment presented greater improvement in visual episodic memory after treatment than the rest of the patients.

Taken together, these data suggest that the two groups differed in terms of their improvement profile after treatment. They also show that the PMDD group obtained more neurocognitive benefits from pharmacological treatment than the MDDAD group, since these patients present improvements in more cognitive functions. Moreover, the patients from the PMDD group who were treated with SNRI obtained greater improvement in visual episodic memory than the rest of patients. As far as we know, this is the first study to approach improvement in cognitive functions after treatment with antidepressants in clinical groups of this kind, so we do not have a reference framework in which to discuss our conclusions. Nevertheless, in our opinion there is a possible explanation for our findings. An increasing body of literature suggests that patients with remitted MDD show some residual cognitive dysfunctions $s^{4,46,47}$. Conceivably, the severity of MDD in our patients, who were unmedicated, masked possible neuropsychological differences at baseline. When our patients achieved sustained remission there is the possibility that we observed residual neurocognitive deficits that might have been greater in the MDDAD than in the PMDD group. Nevertheless, caution must be taken in interpreting our results, since the lack of a control group in our study does not allow us to test this hypothesis.

All these comments must be made in the light of several methodological limitations inherent in the study of data of this type. This study compares natural groups obtained by means of cluster analysis in a sample selected for a clinical trial. Despite the fact that the clinical groups from our work appear consistently as natural groups in the cluster analysis, the procedure used to obtain them creates several important limitations. The first is that the presence of obsessive-compulsive disorder and post-traumatic stress disorder were exclusion criteria for the clinical trial. Both illnesses are classified as anxiety disorders and both $\mathrm{OCD}^{48}$ and $\mathrm{PTSD}^{49}$ cause neuropsychological deficits. Given that MDD may have one of these two illnesses as a comorbid disorder ${ }^{50,51}$, our data would not be applicable to these combinations of disorders. The second limitation caused by the group generation method is that they are highly asymmetrical, and the PMDD group is much smaller than the MDDAD group. This means that some of the statistical analyses in our work probably 
lacked contrast potency. Undoubtedly, it would have been desirable to have access to more symmetrical groups and a larger-size sample, but, as we noted above, it is difficult to find patients with MDD without a comorbid anxiety disorder. The third limitation is that because of the way in which the clinical groups were obtained no scale was applied during the study to control the severity of the anxiety symptomatology. However, applying MINI before the treatment allowed us to reliably establish that the symptomatology of all the disorders in both groups was in remission after the 24-week treatment. Finally, the presence of a control group might have allowed us to determine the exact level of cognitive performance of our sample, and thus to obtain a richer picture of the neuropsychological deficit of our depressed subjects, and perhaps improve the clinical utility of our study. Yet another important limitation is that some of the tests used in this study do not have parallel forms, which hinders the attribution of improvements in a particular function exclusively to the pharmacological treatment. However, the long time elapsed between the two assessments minimizes the possible practical effect that our sample might have experienced.

To sum up, in a sample selected in order to carry out a clinical trial of the neurocognitive effects of SNRI and SSRI treatments in patients with MDD, two natural groups appeared: an MDDAD group and a PMDD group. In the former, MDD manifests itself with comorbid anxiety disorders; MDDAD patients had suffered more depressive episodes, and have more severe current depressive symptomatology than PMDD patients. Our study also suggests that there are no statistically significant differences in the neuropsychological performance of the two groups of patients before treatment, but that the neurocognitive changes after the pharma- cological treatment indicate the presence of distinct neuropsychological profiles in the two groups. Patients with PMDD obtain greater neurocognitive benefits from the antidepressive treatment, and the subgroup of PMDD patients who were treated with SNRI obtained greater visual episodic memory improvements than the rest. Therefore our study suggests that, whereas suffering from an anxiety disorder comorbid to MDD and having suffered more depressive episodes does not affect neuropsychological performance, it does have a bearing on the type and proportion of cognitive improvement that antidepressive treatment is likely to obtain. Moreover, this phenomenon presents some interactions with the type of antidepressant administered.

\section{Acknowledgements}

We gratefully acknowledge Drs. Airaksinen, Jaeger, and Neumeister for sending us articles related to the topics dealt with in this paper. Disclosure: This study was partially supported by the Consejo Nacional de Ciencia y Tecnología (CONACyT) Fondos Mixtos Edo. De Michoacán Project Number 12037 grant. Additional funding was supplied by grants from the Clínica de Enfermedades Crónicas y Procedimientos Especiales (CECYPE), the Agencia Española de Cooperación Internacional (AECI) and the Vicerectorat de Relacions Internacionals of the Universitat de Barcelona. Escitalopram was purchased with grant No. 27.2 from the Coordinación de la Investigación Científica, Universidad Michoacana de San Nicolás de Hidalgo. Duloxetine was kindly provided by Elly-Lilly de México, S.A. de C.V. The authors report no conflicts of interest. 


\section{References}

1. Rogers MA, Kasai K, Matsuo K, Fukuda R, Iwanami A, Nakagome K, et al. Executive and prefrontal dysfunction in unipolar depression: a review of neuropsychological and imaging evidence. Neurosci Res 2004; 50: 1-11.

2. Austin MP, Mitchell PM, Goodwin GM. Cognitive deficits in depression. Br J Psychiatry 2001; 178: 200-206.

3. Porter RJ, Gallagher P, Thompson JM, Youg AH. Neurocognitive impairment in drug free patients with major depressive disorder. Br J Psychiatry 2003; 182: 214-220.

4. Weiland-Fielder P, Erickson K, Waldeck T, Luckenbaurg DA, Pike D, Boone O, et al. Evidence for continuing neuropsychological impairments in depression. J Affect Disord 2004; 82: 253-258.

5. Sobin C, Sackeim H. Psychomotor symptoms of depression. Am J Psychiatry. 1997; 154: 4-17.

6. Egeland J, Rund BO, Sundet K, Landro NI, Asbjornsen A, Lund A, et al. Attention profile in schizophrenia compared with depression: differential effects of processing speed, selective attention and vigilance. Acta Psychiatr Scand 2003; 108: 276-284.

7. Gualtieri TC, Johnson LG, Benedict KB. Neurocognition in depression: patients on and off medication versus healthy comparison subjects. J Neuropsych Cli N 2006; 18: 217-225.

8. Airaksinen E, Larsson ML, Lundberg I, Forsell Y. Cognitive functions in depressive disorders: evidence from a population based study. Psychol Med 2004; 34: 83-91.

9. MacQueen GM, Galway TM, Hay J, Young LT, Joffe RT. Recollection memory deficits in patients with major depressive disorder predicted by past depressions but not current mood state or treatment status. Psychol Med 2002; 32: 251-258.

10. Harvey PO, LeBastard G, Pochon JB, Levy R, Alliaire JF, Dubois B, et al. Executive functions and updating the contents of working memory in unipolar depression. $\mathrm{J}$ Psychiatr Res 2004; 38: 567-576.

11. Chamberlain R, Sahakian B. Cognition in mania and depression. Psychological models and clinical implications. Curr Psychiatr Rep 2004; 6: 451-458.

12. Jaeger J, Berns S, Uzelac S, Davis-Conway S. Neurocognitive deficits and disability in major depressive disorder. Psychiatry Res 2006; 145: 39-48.

13. MacQueen GL, Campbell S, McEwen BS, Macdonald K, Amano S, Joffe RT, et al. Course of illness, hippocampal function, and hippocampal volume in major depression. Proceedings of the National Academy of Sciences 2003; 100: 1387-1392.
14. Campbell S, Marriott M, Nahmias C, MacQueen GM. Lower hippocampal volume in patients suffering from depression: A meta-analysis. Am J Psychiatry 2004; 161: 598-607.

15. Videbech P, Ravnklide B. Hippocampal volume in depression: A meta-analysis of MRI studies. Am J Psychiatry 2004; 161: 1957-1966.

16. Taylor BP, Bruder GE, Stewart JW, McGrant PJ, Halperin J, Ehrlichman H, et al. Psychomotor slowing as a predictor of fluoxetine nonresponse in depressed patients. Am J Psychiatry 2006; 163: 73-78.

17. Ravnkilde B, Videbech P, Clemmensen K, Egander A, Rasmunsen NA, Rosenberg N. Cognitive deficits in major depression. Scand J Psychol 2002; 43: 239-251.

18. Henry JD, Crawford JR. A Meta-analytic review of verbal fluency deficits in depression. J Clin Exp Neuropsyc 2005; 27: 78-101.

19. Austin MP, Mitchell P, Wilhelm K, Parker G, Hickie I, Brodaty $\mathrm{H}$, et al. Cognitive function in depression: a distinct pattern of frontal impairment in melancholia? Psychol Med 1999; 29: 73-85.

20. Michopoulos I, Zervas IM, Papakosta VM, Tsaltsas E, Papageorgiu C, Manéis T, et al. Set Shifting deficits in melancholic vs. Non-melancholic depression: preliminary findings. Eur Psychiatry 2006; 21: 361-363.

21. Elliott R, Sahakian BJ, McKay AP, Herrod JJ, Robbins TW, Paykel ES. Neuropsychological impairments in unipolar depression: the influence of perceived failure on subsequent performance. Psychol Med 1996; 26: 975-989.

22. Paelecke-Habermann I, Pohl J, Leplow B. Attention and executive functions in remitted major depression patients. J Affect Disord 2005; 89: 125-135.

23. Drewets WC. Neuroimaging and neuropathological studies of depression: implications for the cognitive-emotional features of mood disorders. Cur Opin Neurobiol 2001; 11: 240-249.

24. Koetsier GC, Volkers AC, Tulen JHM, Passchier J, Van der Broek W, Bruijn JA. CPT Performance in major depressive disorder before and after treatment with imipramine or fluvoxamine. J Psychiatr Res 2002; 36: 391-397.

25. Elliott R. The Neuropsychological profile in unipolar depression. Trends Cogn Sci 1998; 11: 447-454.

26. Gorman JM. Comorbid depression and anxiety spectrum disorders. Depress Anxiety 1997; 4: 160-168.

27. Roy- Byrne PP, Stang P, Wittehen HU, Ustan B, Walters EE, Kesler RC. Lifetime panic-depression comorbidity in the National Survey Association with symptoms impairment, course and help-seeking. Br J Psychiatry 2000; 176: 229-235. 
28. Airaksinen E, Wahlin Å, Larsson M, Forsell Y. Cognitive and social functioning in recovery from depression: results from a population-based three-year follow-up. J Affect Disord 2006; 96, 107-110.

29. Basso MR, Bornstein RA Relative memory deficits in recurrent versus first episode major depression on a wordlist learning task. Neuropsychology 1999; 13: 557-563.

30. Battista-Cassano G, Puca, F, Scapicchio PL, Trabucchi M. Paroxetine and fluoxetine effects on mood and cognitive functions in depressed nondemented elderly patients. J Clin Psychiat 2002; 63: 396-402

31. Constant EL, Adam S, Gillain B, Seron X, Bruyer R., Seghers, A. Effects of sertraline on depressive symptoms and attentional and executive functions in major depression. Depress Anxiety 2005; 21: 78-89

32. Gallassi R, Di Sarro R, Morreale A, Amore M. Memory impairment in patients with late-onset major depression: the effect of antidepressant therapy. J Affect Disord 2006; 91: 243-250.

33. Herrera-Guzmán I, Gudayol-Ferré E, Lira-Mandujano J, Herrrera-Abarca J, Herrera-Guzmán D, Montoya-Pérez K, et al. Cognitive predictors of treatment response to bupropion and cognitive effects of bupropion in patients with major depressive disorder. Psychiatr Res 2007; 160: 72-82

34. Levkowitz Y, Catfori R, Avital A, Ritcher-Levin G. The SSRI drug fluoxetine but not the noradrenergic tricyclic drug desipramine, improves memory performance during acute major depression. Brain Res Bull 2002; 58: 345-350

35. Fergusson JM, Wesnes KA, Schwartz GE. Reboxetine versus paroxetine versus placebo: Effects on cognitive functioning in depressed patients. Int Clin Psychopharm 2003; 18: 9-14.

36. Sheehan DV., Lecrubier Y, Sheehan KH, Amorim P, Janavs J, Weiller E, et al. The Mini-International Neuropsychiatric Interview (M.I.N.I.): the development and validation of a structured diagnostic psychiatric interview for DSM-IV and ICD-10. J Clin Psychiat 1998; 20: 22-23.

37. Lezak MD, Howiesson DB, Loring DW. Neuropsychological Assessment. Fourth Edition. New York: Oxford University Press; 2004.

38. Robbins TW, James M, Owen AM, Sahakian BJ, McIness L, Rabitt P. Cambridge Neuropsychological Test Automated Battery (CANTAB): A factor analytic study of a large sample of normal elderly volunteers. Dementi 1994; 5: 266-281.

39. DeLuca AK, Lenze EJ, Mulsant BH, Butters MA, Karp JP, Dew MA, et al. Comorbid anxiety disorder in late life depression: Association with memory decline over four years. Int J Geriatr Psychiatry 2005; 20: 848-854.

40. Tarbuck AF, Paykel ES. Effects of major depression on the cognitive function of younger and older subjects. Psychol Med 1995; 25: 285-295.
41. Ilsley JE, Moffoot AP, O'Carroll RE. An analysis of memory dysfunction in major depression. J Affect Disord 1995; 35: 1-9.

42. Palmer BW, Boone KB, Lesser IM, Wohl MA, Berman N, Miller BL. Neuropsychological deficits among older depressed patients with predominantly psychological or vegetative symptoms. J Affect Disordd 1996; 41: 17-24.

43. Purcell R, Maruff P, Kyrios M, Pantelis C. Neuropsychological function in young patients with unipolar major depression. Psychol Med 1997; 27: 1277-85.

44. Fossatti P, Harvey PO, Le Bastard G, Ergis AM, Jouvent R, Alliaire JF. Verbal memory performance of patients with a first depressive episode and patients with unipolar and bipolar recurrent depression. J Psychiatr Res 2004; 138: 137-144

45. Lampe IK, Sitskoon MM, Heeren TJ. Effects of recurrent major depressive disorder on behavior and cognitive function in female depressed patients. Psychiatry Res 2004; 125: 73-79.

46. Ferrier IN, Stanton BR, Kelly TP,Scott J. Neuropsychological function in euthymic patients with bipolar disorder. Br J Psychiatry 1999; 175: 246 -251.

47. Nebes, RD, Pollock BG, Houck PR, Butters MA, Mulsant BH, Zmuda MD, et al. Persistence of cognitive impairment in geriatric patients following antidepressant treatment: A randomized, double-blind clinical trial with nortriptyline and paroxetine. J Psychiatr Res 2003; 37: 99-108.

48. Kuekz AK, Hohagen F, Voderholzer V. Neuropsychological performance in obsessive-compulsive disorder: A critical review. Biol Psychol 2004; 65: 185-236.

49. Bremmer JD. The relationship between cognitive and brain changes in posttraumatic stress disorder. Ann N Y Acad Sci 2006; 1071: 80-86.

50. Fava M, Rankin MA, Wright EC, Alpert E, Nierenberg AA, Pava J, et al. Anxiety disorders in major depression. Compr Psychiatry 2000; 41: 97-102.

51. Kaufman J, Charney D. Comorbidity of mood and anxiety disorders. Depress Anxiety 2000; 12 (suppl 1): S69-S76.

\footnotetext{
Address for correspondence:

Joan Guàrdia Olmos

Departament de Metodologia

Facultat de Psicologia

Universitat de Barcelona

Passeig de la Vall d'Hebron, 171

08035 Barcelona (Spain)

Phone no. +34933125090

phone/fax +34934021359

E-mail address: jguardia@ub.edu
} 